\title{
Nueva York Agonizante: crisis de identidad urbana
}

\author{
Michelle A. ERAzO \\ Universidad Complutense de Madrid \\ micha.erazo@gmail.com
}

Recibido: 5 de abril de 2011

Aceptado: 20 de mayo de 2011

\section{Resumen}

En este artículo se trata de reconocer la sociedad enferma a través de lo que proyectan las ciudades, nuestro hogar. Nos hemos autonombrado civilización, hemos edificado a nuestro alrededor un refugio. Pero la sociedad siempre cambiante ha perdido el control. Nace, producto de nuestra realidad, el término de "no-lugar" y se define paralelamente el de lugar. La hipótesis que se defiende en la post-modernidad es que esta es productora o generadora de dichos no-lugares, de espacios que no son en sí lugares antropológicos y que no integran los lugares antiguos, los lugares de fundación, los lugares de memoria. Las metrópolis son organismos vivos, asfalto que respira. Reconociéndolas como seres vivos podemos interpretar el deterioro que sufren. Las ciudades congestionadas tienden a padecer altibajos, "enferman" y van revelando sus síntomas. Síntomas que son provocados por la veloz metamorfosis del estilo de vida actual. Paralelamente a la pérdida de identidad étnica, tenemos la pérdida de identidad urbana. Se diluyen los rasgos de la diversidad antropológica.

Palabras clave: enfermedades urbanas, postmodernidad, globalización, no-lugar.

Title: Fading New York: Urban identity crisis

\section{Abstract}

This article is about recognizing the sick society, looking through which cities, our homes, project. We have self-appointed as civilization, we have built a shelter around us. But the ever-changing society has lost control. As a result of our reality, born the term non-place in parallel to place. The hypothesis defended in is that post-modernity is producer or generator of the non-place spaces that are not themselves anthropological places and ancient sites. They are not part of the foundation places, not places of memory. The cities are living organisms, asphalt breathing. Acknowledging them as living beings we can interpret the wear and tear. Congested cities tend to have ups and downs; their "getting sick" reveal us their symptoms. Same symptoms are caused by the fast metamorphosis of the modern lifestyle. Parallel to the loss of ethnic identity, we have the loss of urban identity. It dilutes the features of the anthropological diversity.

Keywords: urban diseases, post-modernity, globalization, non-place. 


\section{Índice}

1. Introducción

2. Urbe-alzhéimer

3. Síndrome del desarraigo ciudadano

4. Auto-anulación metropolitana (soledad intensiva)

5. Ciudades bipolares

6. Conclusión

\section{Introducción}

Creemos conocer el mundo sobre el cual caminamos, es más, estamos convencidos del control que tenemos del espacio. Nos hemos autonombrado civilización, hemos edificado a nuestro alrededor un refugio. Pero la sociedad siempre cambiante ha perdido el control. Nace, producto de nuestra realidad, el término de "nolugar", que se define paralelamente al de lugar. La hipótesis que se defiende en la post-modernidad es que esta es productora 0 generadora de dichos no-lugares, de espacios que no son en sí lugares antropológicos y que no integran los lugares antiguos, los lugares de fundación, los lugares de memoria.

Las metrópolis son organismos vivos, asfalto que respira. Así se puede interpretar el deterioro que sufren.

El concepto es que existen espacios: si un lugar puede definirse como lugar de identidad, relacional e histórico, un espacio que no puede definirse ni como espacio de identidad ni como relacional ni como histórico, definirá un no lugar. (Auge 1993: 83)

Las ciudades congestionadas tienden a padecer altibajos, se "enferman" y van revelándose sus síntomas, conforme se avanza en esta alienación de nuestra sociedad cada vez menos apegada a la fisicidad, nos vamos descubriendo como una masa homogénea que no permite fijar una identidad $y$, mucho menos, un respeto a nuestro refugio original.

Hablando metafóricamente podemos recrear un "historial clínico" de las grandes ciudades víctimas de esta epidemia causada por sus mismos creadores, podemos individuar ciertos síntomas.

\section{Urbe-alzhéimer}

La ciudad tal como la describe Luc Sante en su texto Low life es un ente que se degenera. Según Sante (1999), Nueva York es una ciudad, pero de igual modo es una criatura que se enferma, un ser vivo vulnerable a las amenazas del ambiente, del tiempo, a las infecciones. Esta se ha convertido en víctima de una amnesia 
incurable, es la ciudad del olvido; destinada a marcar su cuerpo con señales que la identifiquen perennemente. Caminar por sus calles no tiene ya ningún valor sentimental. Se ha quedado sin referencias espaciales, recorridos que son como venas vacías (sin sangre), sus calles van numeradas y orientadas por un orden metodológico y no por la historia o sus recuerdos.

Hoy en día, los no-lugares son inevitables, tienen el poder de aparecer con simples vocablos (esos que impregnan las calles), se exhiben como textos alrededor de cualquier espacio y lo transforman con sus señales. El valor emotivo de los espacios nace del tránsito y la permanencia de sus habitantes, no por los letreros que los definen. Reciben su valor a través de quien vive en ellos.

Es así como, de manera antinatural, son dictadas las condiciones (normas) de circulación; en los espacios donde se considera a priori que los individuos no interactúan sino con los textos, ya no hay interlocución, solo instituciones (aeropuertos, compañías de aviación, ministerio de transportes, sociedades comerciales, policía caminera, municipalidades). Esta esencia se materializa a través de los mandatos, los consejos, los comentarios, los "mensajes" transmitidos por los innumerables "soportes" (carteles, pantallas, afiches) que forman parte integrante del aberrante paisaje contemporáneo. La enfermedad afecta al control del pensamiento, la memoria y el lenguaje. Los ciudadanos pierden toda fuerza de permanencia ante la ciudad post-moderna repleta de tatuajes que hacen recordar que es indomable.

Haciendo una comparación con el film Memento (Nolan 2000), donde el protagonista, después de un accidente, sufre de una amnesia continua y no logra registrar ningún nuevo acontecimiento (a este accidente podríamos Ilamarlo Globalización), por cada cosa importante que sabe que olvidará se tatúa la piel (la ciudad Ilena de referencias).

Las ciudades se tatúan para no olvidar lo que son, y al mismo tiempo para recordarles a los transeúntes que la ciudad misma se olvida de ellos, y que cada vez que un ciudadano inicia su rutina, se levanta, sale de su casa, las indicaciones siguen ahí, como si fuese la primera vez que las leyese. Como un eterno extranjero, mira las calles y las indicaciones, lee atentamente el menú de la misma cafetería que frecuenta diariamente y lee el precio de lo que pide todas las mañanas en el tablón frente a la caja, entra al edificio donde le piden su identificación para acceder al ascensor donde siempre se le preguntará el nivel al que se dirige, aunque sea siempre el mismo. 


\section{Síndrome del desarraigo ciudadano}

Hablemos del desapego mutuo entre el nomadismo actual que forma parte del modus vivendi del hombre y el rechazo de las ciudades mismas hacia el intruso pasajero. El espacio del extranjero, el eterno errante, que busca la identificación temporal en los sitios de su viaje. La imagen anticipada de un lugar desprende una emoción, una ambición, una necesidad de conquista territorial.

Siguiendo esta visión "romántica" del viaje, nos encontramos con la imagen de la Tierra Prometida, su imagen anticipada que no habla más que superficialmente, pero que inyecta la necesidad de sentirse arraigado en ese hipotético allá.

De modo particular, debido al origen y la anatomía de Nueva York, el efecto de desarraigo no se desvanece con el hecho de tocar tierra. Al igual que las ciudades celestes, que tienen su contraparte en el cosmos, esta ciudad ha logrado desdoblar su identidad, ya que conviven la Nueva York Terrenal -casi infernal- y la Nueva York virtualmente celeste en el mismo espacio pero en diversas dimensiones.

La identidad del neoyorkino termina por no existir y sucumbe al anonimato. Los lugares de tránsito se multiplican y, dentro de ellos, el diálogo se reduce a la lectura de los textos indicativos que estos proponen. Ya no hace falta interactuar o crear una comunidad para vivir dentro de Nueva York.

\section{Auto-anulación metropolitana (soledad intensiva)}

La soledad selectiva es una enfermedad relativamente actual; bastó que la humanidad fuera autosuficiente para evitar a toda costa la colaboración. El ser humano post-moderno no puede sobrevivir solo aunque así lo crea. Nueva York al parecer tiene miedo a desaparecer; por eso continúa jugando a ser inalcanzable. Tiene claro que la búsqueda continua de la tierra que desaparece es suficiente para suscitar el interés del pasajero, extranjero, inmigrante, que todavía trata de percibirla y apropiarse de ella. La ciudad contagia al habitante el temor de perderse en una ciudad que no se deja conquistar.

La ciudad es víctima de un curioso vértigo de existencia, al igual que sus creadores (los seres humanos), basado en la lógica versus la fe; algo parecido a lo que dijese Douglas Adams sobre Dios en su novela Guía del autoestopista galáctico:

Su argumento es más o menos el siguiente: "Me niego a demostrar que existo", dice Dios, "porque la demostración anula la fe, y sin fe no soy nada".

"Pero", dice el hombre, "el pez Babel es una revelación brusca, ¿no es así? No pudo haber evolucionado al azar. Demuestra que Vos existís, 
y por lo tanto, según vuestros propios argumentos, Vos no. Quod erat demonstrandum".

"iVálgame Dios!", dice Dios, "no había pensado en eso", y súbitamente desaparece en un soplo de lógica. (Adams 1991: 35)

De manera análoga, la ciudad sufre el vértigo de desvanecerse en su realidad. Se crea, recrea y vive de la idea que se tiene de ella misma, porque justo cuando ésta se transforme en una ciudad concreta, conquistada y no mítica, ideal, súbitamente desaparecerá en un soplo de realidad donde no basta ser conocida como el sueño americano por excelencia.

En cierto modo, existe un doble aspecto del ciudadano: la pérdida del sujeto en la muchedumbre o contrariamente el poder absoluto, reivindicado por la conciencia individual.

La soledad es una enfermedad contemporánea; la causa: "the lack of identity" (o laguna de identidad) (Sante 1999: 120). Los efectos de esta soledad están ligados directamente a la proliferación de los no-lugares. La sociedad considera que un no-lugar designa dos realidades complementarias pero distintas: los espacios constituidos con relación a ciertos fines típicos del presente (el tránsito, el ocio, el marketing) y la relación que los individuos mantienen con dichos espacios, realidades que la ciudad engendra para homogeneizar el flujo de la ciudadanía. Estas dos relaciones se superponen bastante ampliamente pero no logran fundirse, los no-lugares crean la "contractualidad solitaria".

Desde hace tiempo se nota la inmensa soledad en la ciudad, dentro de ella no se detiene más a observar los rostros, las manos, los gritos, los silencios. La sombra de la soledad oculta detrás de un vidrio apedreado, un gemido, un insulto, un dolor leve en el vientre del que cruza una calle por la noche; la sombra de la angustia en la mirada de una mujer que espera la llegada a casa de su hijo. El cuerpo de la soledad crece y se extiende, casi líquido, sobre el asfalto. Como un muro invisible, ciega el alma. Y la altera.

La soledad es hoy ausencia en el exceso. Carencia en la opulencia. El vacío que estalla al centro de la multitud. Nada hay en lo pleno, en lo grandioso, en lo atiborrado.

La soledad en la ciudad cobra la forma de una garra. No es la soledad compartida que, por ejemplo, provoca una obra de arte. La soledad del artista plasmada en la obra y dirigida hacia otra soledad que le mira y la disfruta. Es eso el arte. Lo íntimo. Pero la otra soledad, la soledad urbana, desconoce al otro. Provoca que todos los habitantes de la misma ciudad nos desconozcamos y nos ignoremos. Es la soledad que brota del miedo. El miedo a la violencia, al grito, a la impunidad que se apodera a gran velocidad del mundo. (Cortina 2008) 


\section{Ciudades bipolares}

Podemos también interpretar como un problema de la psique colectiva la bipolaridad de las ciudades. Este es un desorden en el que la urbe que la padece (prácticamente todas las grandes metrópolis) presenta unas manifestaciones extremas de dos estados de ánimo principales, los cuales se conocen como el polo depresivo y el polo maníaco o de euforia. Estos estados de ánimo fluctúan en la urbe de forma cíclica e inconsistente; por momentos sufre de una depresión grave 0 crónica $y$, de repente, puede presentarse totalmente eufórica.

Uno de los indicativos principales de una ciudad que padece de bipolaridad es que la misma presenta estos polos de forma extrema y exagerada.

Podemos encontrar dicho "comportamiento" en el colectivo urbano: la ciudad es un órgano vivo por sí mismo, que puede pasar por periodos de grave devaluación y, a la semana, siguiente celebrar un festival; puede perder las torres gemelas y, unos días más tarde, organizar un concierto benéfico, o la semana de la moda, y olvidar lo acontecido; puede sufrir de violencia cotidiana y ser la ciudad más vigilada; puede presenciar una huelga de inmigrantes y estar rodando un film la semana siguiente. La ciudad sabe, en su consciencia, que es una ciudad adolescente $y$, apenas cambia de humor, su inconsciente le hacer creer que es una ciudad celeste.

\section{Conclusión}

Es reina y pordiosera al mismo tiempo, incapaz de prever el estado de su propio tesoro que varía a merced de bruscas penurias y manías inexplicables. Nueva York siempre tiene demasiada abundancia y también demasiada sequía. (Charyn 1999: 118)

Podemos recurrir al interés que pueden suscitar las raíces históricas de las ciudades, pero el cambio de era provocado por la tecnología de nuestros tiempos, de la cual ahora somos dependientes, no se debe tomar como una amenaza a la identidad. Si sabemos mirar para adelante teniendo claro el camino recorrido hasta ahora.

Para reencontrar la autenticidad de las ciudades no sirve de mucho tratar de recobrar el pasado, sino que es necesario continuar el camino ya comenzado y no saltarse a una autopista que lleva a la estandarización de la sociedad. El goce de la diversidad autóctona no entra en conflicto con la sociedad hodierna. Las ciudades solo pueden perecer si se deja de fluir dentro de ellas.

La expansión de las ciudades en la actualidad genera suburbes; infinidad de grupos culturales que crean una aparente diversidad pero que terminan por proliferar en todas las grandes ciudades: los china towns, las Little Italies, el barrio latino, etc. Todos 
aquellos grupos étnicos que creen haber encontrado una identidad sucumben también al estereotipo de la ciudad cosmopolita; se deforman en una identidad fragmentada y entretejida entre tantas culturas diversas que se ha perdido la huella de los rasgos autóctonos de dichas urbes.

\section{Bibliografía}

ADAMS, Douglas (1991): Guía del autoestopista galáctico. Barcelona: Anagrama.

AUGÉ, Marc (1993): Los no lugares: espacios del anonimato. Buenos Aires: Gedisa.

CHARYN, Jerome (1999): New York, chronicle of the urban jungle. Barcelona: Ediciones $\mathrm{B}$.

CORTINA, María (2008): "La soledad urbana" [en línea]. Crónica de hoy, $06 / 10 / 2008$.

En: http://www.cronica.com.mx/nota.php?id nota $=389292$ [Consulta: abril de 2011].

KOOLHAAS, Rem (2004): Delirio de Nueva York. Barcelona: Gustavo Gili.

NOLAN, Christopher (dir.) (2000): Memento. USA: Newmarket Capital Group / Team Todd / I Remember Productions / Summit Entertainment.

SANTE, Luc (1999): Low Life: Lures and Snares of Old New York. USA: Vintage Departures. 